\title{
CORRECTION
}

\section{Correction: The impact of antenatal cannabis use on the neonate: time for open engagement?}

Rachana Singh (ID, DeWayne M. Pursley, Jonathan M. Davis on behalf of the Pediatric Policy Council*

(c) The Author(s), under exclusive licence to the International Pediatric Research Foundation, Inc 2021

Pediatric Research (2022) 92:609; https://doi.org/10.1038/s41390-021-01788-w

Correction to: Pediatric Research https://doi.org/10.1038/s41390021-01591-7, published online 11 June 2021

In the The Pediatric Policy Council section of this article, societies were named which are US national societies and are not based in Boston MA. The section should read correctly:

THE PEDIATRIC POLICY COUNCIL
Shetal Shah ${ }^{5}$, Jean Raphael ${ }^{6}$, Mona Patel $^{6}$, Jonathan Davis ${ }^{7}$, DeWayne Pursley ${ }^{7}$, Tina Cheng ${ }^{8}$, Sherin Devaskar ${ }^{8}$, Joyce Javier ${ }^{9}$ and Lois Lee ${ }^{9}$

${ }^{5}$ Pediatric Policy Council (PPC), McLean, Virginia, USA; ${ }^{6} \mathrm{PPC}$ from Academic Pediatric Association, McLean, Virginia, USA; ${ }^{7}$ PPC from Association of Medical School Pediatric Department Chairs, McLean, Virginia, USA and ${ }^{8}$ PPC from Society for Pediatric Research, The Woodlands, Texas, USA.

The original article has been corrected. 